\title{
Operative balloon dilatation for pulmonary atresia with intact ventricular septum
}

\author{
J R L HAMILTON, S F FONSEKA, N WILSON, D F DICKINSON, D R WALKER \\ From the Regional Paediatric Cardiothoracic Unit, Killingbeck Hospital, Leeds
}

SUMMARY In six infants with pulmonary atresia and intact ventricular septum operative balloon dilatation was used to achieve continuity between the right ventricle and the main pulmonary artery as the initial procedure. Two of the six subsequently needed an aortico pulmonary shunt. All six are alive and well.

Pulmonary atresia with intact ventricular septum is a rare abnormality, which is usually lethal within the first few weeks of life. ${ }^{1}$ Surgical results have improved after the introduction of prostaglandin $\mathrm{E}$ infusion to maintain ductal patency ${ }^{2}$ thus permitting the surgeon to operate on infants who are in better biochemical and haemodynamic condition. It is generally agreed that operation should provide not only adequate pulmonary blood flow but also anterograde flow through the right ventricular outflow tract in order to decompress the ventricle and encourage growth of both the right ventricle and the tricuspid valve ring. Recent papers have recommended valvotomy combined with a shunt procedure, either via a right thoractomy with a Waterston shunt ${ }^{3}$ or a left sided approach combining a modified BlalockTaussig shunt with transpulmonary valvotomy. ${ }^{4}$

Percutaneous balloon valvuloplasty for pulmonary stenosis ${ }^{5-7}$ has given encouraging initial results. We therefore decided to attempt dilatation of the atretic pulmonary valve using a balloon introduced via the right ventricle at operation. This paper presents our initial experience.

\section{Patients and methods}

Over a ten month period in 1986 , six consecutive infants presenting with pulmonary atresia and intact ventricular septum were managed with an initial operative pulmonary balloon dilatation. According to the classification of Bull and colleagues, ${ }^{8}$ all our

Requests for reprints to Mr J R L Hamilton, FRCS, Killingbeck Hospital, York Road, Leeds LS14 6UQ.

Accepted for publication 22 June 1987 cases had a hypoplastic but tripartite right ventricle (inlet, trabecular, and infundibular portions) with patency of the right ventricular outflow tract up to the level of the imperforate valve. The tricuspid valve annulus measured on the preoperative angiogram (4 cases) or echocardiogram ( 2 cases) varied in diameter from 7 to $12 \mathrm{~mm}$. The figure shows a typical angiogram. They are therefore in the group which would seem to have an anatomy which is most favourable from the surgical viewpoint. The table gives details of the patients.

All infants were treated initially with intravenous prostaglandin $\mathrm{E}$ infusion after echocardiographic diagnosis. Operative balloon dilatation was performed after angiography and balloon atrial septostomy in cases $1,2,3$, and 4 but patients 5 and 6 were accepted for operation on the basis of the ultrasound examination alone without septostomy. Patient 3 was stabilised on oral prostaglandin ${ }^{9}$ but was then readmitted with increasing cyanosis at nine weeks of age.

A median sternotomy was used in all cases and the heart was elevated by swabs placed in the posterior pericardium. A standard $10 \mathrm{~mm}$ external diameter balloon dilatation catheter was used (Meditech). The balloon catheter was tested to assess the volume of saline required to produce a firm inflation. A purse-string suture was placed in the anterior wall of the right ventricle and the catheter was introduced via a stab incision. It was advanced by palpation up to and then through the atretic valve using firm pressure. With the catheter and balloon positioned across the valve ring the balloon was inflated three times with the predetermined volume of saline. Any bradycardia was allowed to recover before reinflation. The catheter was withdrawn and the purse-string tied. 

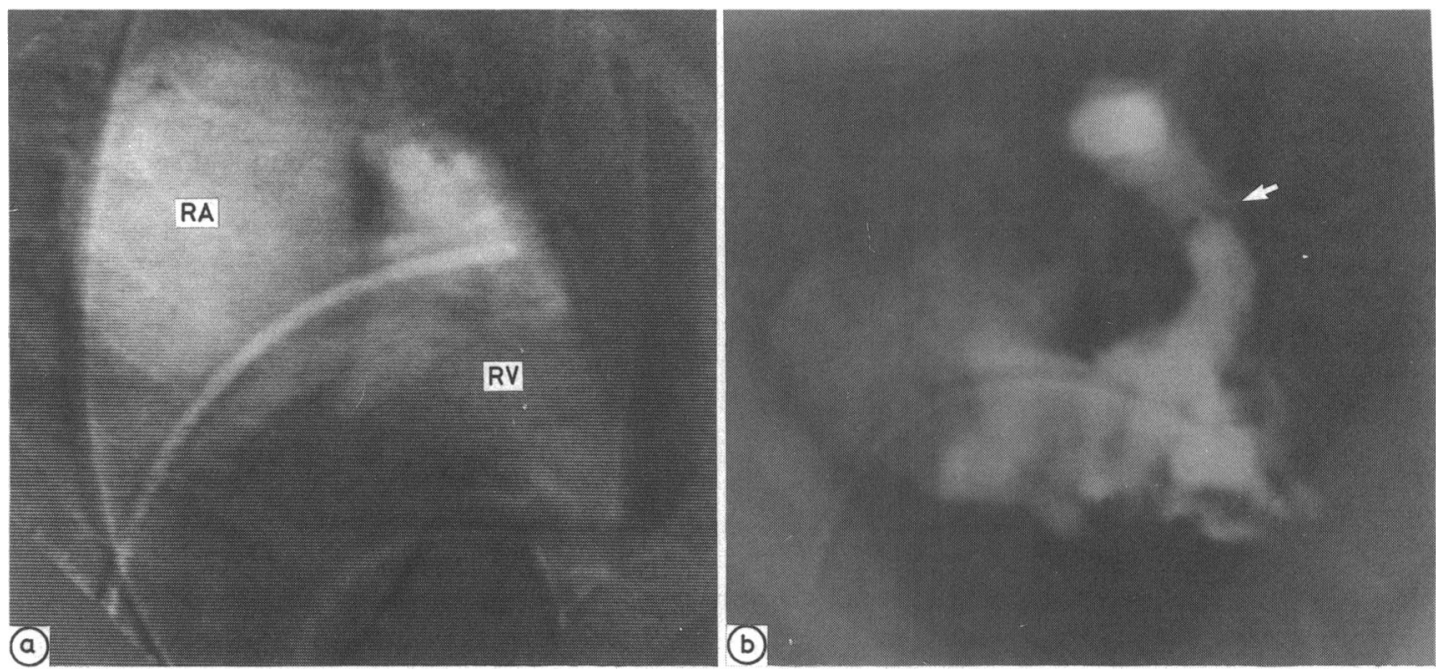

Fig Right ventricular angiograms in cases 1 and 5. (a) Digital subtraction right ventricular angiogram in patient 1 before operation. The ventricle is well developed up to the level of the imperforate valve but the trabecular zone is poorly opacified. There is considerable tricuspid regurgitation. (b) Digital subtraction right ventricular angiogram in patient 5 six months after operation. The right ventricle is tripartite but the trabecular portion is partially obliterated by hypertrophied muscle bundles. The dysplastic, but now perforate, pulmonary valve membrane is arrowed. $R A$, right atrium; $R V$, right ventricle.

Table Patient details at the time of operation

\begin{tabular}{lllll}
\hline Case & $\begin{array}{l}\text { Age } \\
\text { (days) }\end{array}$ & $\begin{array}{l}\text { Weight } \\
(\mathrm{kg})\end{array}$ & Sex & $\begin{array}{l}\text { Balloon atrial } \\
\text { septostomy }\end{array}$ \\
\hline 1 & 12 & $3 \cdot 6$ & $\mathrm{M}$ & + \\
2 & 3 & $2 \cdot 2$ & $\mathrm{M}$ & + \\
3 & 60 & $3 \cdot 8$ & $\mathrm{M}$ & + \\
4 & 1 & $3 \cdot 3$ & $\mathrm{~F}$ & + \\
5 & 17 & $3 \cdot 0$ & $\mathrm{M}$ & - \\
6 & 2 & $3 \cdot 6$ & $\mathrm{M}$ & - \\
\hline
\end{tabular}

\section{Results}

The valve was felt to "give" in each case during inflation. The length of the standard dilatation catheter caused problems, however. In one infant (case 4) inflation produced a tear in the right ventricular outflow tract, resulting in considerable blood loss. In case 2 this problem was anticipated because the baby was so small and the technique was modified. An embolectomy catheter was used instead, and the inflated balloon was withdrawn across the valve.

Prostaglandin E infusion was continued in all the infants postoperatively until blood gases were satisfactory. Prostaglandin treatment could not be withdrawn in cases 4 and 5 and Waterston shunts were constructed 14 and 21 days after the dilatation. The remaining patients were extubated $1,3,5$, and 7 days after operation. All six patients are alive, gaining weight, and developing normally 6-16 months after operation (median 11 months). Patient 5 underwent an uneventful repair of a cleft palate four months after the dilatation. Re-evaluation by cardiac catheterisation was carried out at six months and showed that right ventricular pressure was $75 \%$ of the systemic pressure. He is now awaiting surgical reconstruction of the right ventricular outflow tract. Postoperative Doppler ultrasound examination of cases $1,2,3,4$, and 6 showed a pressure drop of 15 , $80,40,10$, and $20 \mathrm{~mm} \mathrm{Hg}$ respectively between the right ventricle and the main pulmonary artery. Patient 2 was recatheterised six months after the procedure. The investigation confirmed a high right ventricular pressure but the pulmonary valve could not be crossed. However, the right ventricular cavity was well developed and no tricuspid regurgitation was detected. He recently underwent successful reconstruction of his right ventricular outflow tract on cardiopulmonary bypass.

\section{Discussion}

Before the introduction of prostaglandin infusion to maintain ductal patency the results of pulmonary valvotomy alone as the initial palliative measure for these infants were very poor with some workers reporting $100 \%$ mortality. ${ }^{3}$ As a result systemic to pulmonary artery shunts were advocated but follow up of these patients demonstrated lack of devel- 
opment of the right ventricle and tricuspid valve. A morphological study by Bull and colleagues showed that the small right ventricular cavity was in many cases caused by massive hypertrophy. ${ }^{8}$ It was suggested that this would regress if the ventricle was decompressed. They also suggested that the pulmonary valve annulus was usually adequate to support the circulation and that the limitation to forward flow was the size of the tricuspid valve annulus. In a study from the same group, de Leval et al reported angiographic evidence of growth of the tricuspid annulus which was greatest if right ventricle to pulmonary artery continuity was established early in life. ${ }^{4}$ On the basis of this, and combined with their poor results with valvotomy alone, they recommend a left thoracotomy and creation of a modified Blalock-Taussig shunt with a transpulmonary valvotomy.

In contrast, Dobell and Grignon argued in favour of an initial valvotomy, performed via a median sternotomy and with Hegar dilators to open the valve. ${ }^{10}$ They emphasised that improvement is not immediate and time must be given to allow the oedema to settle. As the right ventricle decompresses the compliance will improve and forward flow will increase.

Whatever the preferred technique, all are agreed that pulmonary artery to right ventricular continuity should be established as soon as possible. It seems unnecessary to use cardiopulmonary bypass to perform an open valvotomy or valvectomy although inflow occlusion during this procedure has been advocated. ${ }^{11}$ Blind transventricular valvotomy with dilators cannot offer maximum dilatation and even the advocates of transpulmonary valvotomy in the beating heart (using an embolectomy balloon to occlude the right ventricular outflow) admit that exposure of the pulmonary valve is not ideal. ${ }^{11}$ On the basis of our initial experience we feel that the balloon catheter introduced via a small stab incision in the right ventricle circumvents some of these difficulties and offers a rapid, simple method of providing maximum dilatation of the valve with minimal trauma to the ventricle.

In pulmonary atresia with an intact ventricular septum there is a range of right ventricular cavity sizes varying from severely hypoplastic to dilated. ${ }^{12}$ Morphological studies $^{1213}$ and surgical series ${ }^{3410}$ suggest that cases with a right ventricle which is sufficiently well developed to allow continuity to be established between the right ventricle and the pulmonary artery in the neonatal period without the addition of a pulmonary to systemic artery shunt are in the minority. Nevertheless, these cases should be identifiable at the preoperative imaging study, whether angiography or ultrasound, and they seem to be suitable for a comparatively simple procedure to decompress the right ventricle and establish an adequate pulmonary blood flow. Balloon atrial septostomy was performed in four of our patients because we had previously followed the management plan for these patients outlined by Patel and colleagues. ${ }^{14}$ However, if dilatation is to be performed without a shunt then a high right atrial pressure might be desirable in order to promote forward flow of blood through a relatively non-compliant right ventricle. In these circumstances atrial septostomy seems to be contraindicated.

Ring et al studied the effects of balloon dilatation on the pulmonary valve annulus in lambs and observed that the main area of trauma was not the annulus but rather the right ventricular outflow tract. ${ }^{15}$ We believe this area of trauma results in oedema which can be a major cause of obstruction to blood flow immediately after operation. Accordingly we continued the prostaglandin infusion postoperatively until flow through the valve improved. With this policy, we accept a slower postoperative recovery than if a shunt had been constructed simultaneously, and also accept that a shunt may be necessary in some patients at a later stage if they remain prostaglandin dependent. The considerable advantage is that unnecessary shunts are avoided.

The main problems were associated with the size of the standard dilatation balloon catheter which has a $1 \mathrm{~cm}$ tip distal to a $3 \mathrm{~cm}$ balloon. In neonatal hearts the tip of this catheter impinges on the bifurcation of the pulmonary artery while the proximal shoulder of the balloon distends the right ventricular outflow tract. A $0.5 \mathrm{~cm}$ guiding tip and a $1.5 \mathrm{~cm}$ balloon would be more appropriate for use in neonatal hearts and we hope soon to try a modified balloon catheter.

\section{References}

1 Freedom RM, Keith JD. Pulmonary atresia with normal aortic root. In: Keith JD, Rowe RD, Vlad P, eds. Heart disease in infancy and childhood. 3rd ed. London, New York: Macmillan, 1978:506-17.

2 Olley PM, Cocceani F, Bodach E. E-type prostaglandins. A new emergency therapy for certain cyanotic congenital heart malformations. Circulation 1976;53:728-31.

3 Moulton AL, Bowman FO, Edie RN, et al. Pulmonary atresia with intact ventricular septum: sixteen year experience. $J$ Thorac Cardiovasc Surg 1979; 78:527-36.

4 de Leval M, Bull C, Stark J, Anderson RH, Taylor JFN, Macartney FJ. Pulmonary atresia and intact ventricular septum: surgical management based on a revised classification. Circulation 1982;66:272-80.

5 Lababidi Z, Jiunn-ren W. Percutaneous balloon pulmonary valvuloplasty. Am J Cardiol 1983;52:560-2.

6 Kan JS, White RI, Mitchell SE, Anderson JH, Gardner TJ. Percutaneous transluminal balloon 
valvuloplasty for pulmonary valve stenosis. Circulation 1984;69:554-60.

7 Tynan M, Baker EJ, Rohmer J, et al. Percutaneous balloon pulmonary valvuloplasty. $\mathrm{Br}$ Heart $J$ 1985;53:520-4.

8 Bull C, de Leval MR, Mercanti C, Macartney FJ, Anderson RH. Pulmonary atresia and intact ventricular septum: a revised classification. Circulation 1982;66:266-71.

9 Silove ED, Coe JY, Shiu MF, et al. Oral prostaglandin E2 in ductus dependent pulmonary circulation. Circulation 1981;63:682-8.

10 Dobell ARC, Grignon A. Early and late results in pulmonary atresia. Ann Thorac Surg 1977;24:264-74.

11 Moulton AL, Malm JR. Right ventricular outflow tract obstruction. In: Stark J, de Leval M, eds. Surgery for congenital heart defects. London, New York: Grune and Stratton, 1983:305-6.

12 Zuberbuhler JR, Anderson RH. Morphological variations in pulmonary atresia with intact ventricular septum. Br Heart J 1979;41:281-8.

13 Freedom RM, Dische MR, Rowe RD. The tricuspid valve in pulmonary atresia and intact ventricular septum. Arch Pathol Lab Med 1978;102:28-31.

14 Patel RG, Freedom RM, Moes CAF, et al. Right ventricular volume determinations in 18 patients with pulmonary atresia and intact ventricular septum. Analysis of factors influencing right ventricular growth. Circulation 1980;61:428-40.

15 Ring JC, Kulik TJ, Burke BA, Lock JE. Morphologic changes induced by dilation of the pulmonary valve annulus with overlarge balloons in newborn lambs. Am J Cardiol 1984;55:210-4. 